\title{
Designing a sustainable logistics supply chain
}

\author{
Svetlana Suvorova $^{1 *}$, Oksana Kulikova $^{2}$, and Natalja Tropynina ${ }^{2}$ \\ ${ }^{1}$ Peter the Great St.Petersburg Polytechnic University, 195251, Polytechnicheskaya, 29, Saint \\ Petersburg, Russia \\ ${ }^{2}$ Saint Petersburg State University of Industrial Technologies and Design, 191186, Bolshaya \\ Morskaya, 18, Saint Petersburg, Russia
}

\begin{abstract}
The purpose of study was to identify the main approaches to the formation of an industry solution related to the design of effective supply chains and aimed at increasing the visibility of constraints and bottlenecks, as well as to prevent unwanted blockages in the logistics process. The work uses general scientific methods of logistics research based on economic and methodological developments in the field of transdisciplinary analysis of modern logistics. The necessity of using a qualitatively new approach of fragmented design of the logistics process, based on a system of values, focused on the new code and digital thinking, in the core of which the cognitive platform is in the real economy sector, has been substantiated. The main components of an industry solution for supply chain visibility and traceability are defined. Conceptualized and theoretically divided into stages the process of designing an effective logistics supply chain that meets the conditions of visibility and traceability. The formation of an industry solution related to the design of a fragmented logistics process and an efficient supply chain is of applied importance and can maximally meet the growing needs of stakeholders to create sustainable multi-level distribution channels of all types of resources.
\end{abstract}

\section{Introduction}

The ongoing market transformation and epidemiological consequences associated with covid-19 have increased trade tensions and affected consumer satisfaction. The resulting upheaval also affected supply chains, which came under increasing pressure to deliver goods in a personalized and low-cost manner. Even before the pandemic, logistics companies, faced with a surge in customer expectations, were forced to focus on delivery flexibility, adjusting speed and urgency. In this context, the supply chain's ability to recover, redirect or replace resources, maintaining its reliability and efficiency, i.e., resilience, is of relevance. However, to achieve actual sustainability, it is necessary to strictly control incoming and outgoing material flows, as well as to monitor and optimize the process of their movement.

The purpose of this study is to identify key approaches to form an industry solution related to the design of efficient supply chains, increasing visibility into possible constraints and bottlenecks, and providing additional channels to prevent logistical process blockages. Visibility (transparency) and traceability help companies meet the growing need of

\footnotetext{
* Corresponding author: suvorova sd@mail.ru
} 
stakeholders for sustainable distribution channels by making sure that sourcing raw materials, converting them into products and getting them to market does not cause environmental, social, or economic damage.

The necessity of genesis of designing an effective logistics supply chain in the real sector of the economy was considered and substantiated in the works of such scientists as: B.A. Anikin, V.A. Gajinsky, V.M. Golperin, S.V. Sarkisov, A.A. Thompson, A.J. Strickland, P. Doyle, P. Drucker, and others. In the works of these authors, the effectiveness of the supply chain was conceptualized and theoretically divided into stages, the identification of which allowed to reveal the nature of integration of the links that create the value of the product at different levels of consumption.

Radical market changes, limited by the pandemic, have clearly shown that supply chains, which have long been cost-effective and reliable, must also be sustainable and stable. Although all industries need effective supply chains, the specific business cases for traceability and solution visibility are not flexible enough and need further elaboration.

\section{Materials and methods}

Visibility and traceability are critical factors for building relationships between counterparties in the supply chain and strengthening collaboration. At the same time, reliability and efficiency remain basic priorities [1], complementing each other in the decision-making process, both at the level of input data and during the transformation of information flows (Tab.1).

Table 1. Visibility and traceability as a supply chain productivity factor.

\begin{tabular}{|c|c|c|c|}
\hline \multicolumn{4}{|c|}{ Visibility and traceability } \\
\hline $\begin{array}{c}\text { Input streams (data) } \\
\text { resources: }\end{array}$ & Labor resources: & Optimisation: & Reuse: \\
\hline $\begin{array}{c}\text { Searching for raw } \\
\text { materials in a } \\
\text { renewable way }\end{array}$ & $\begin{array}{c}\text { Use of Fair Labor } \\
\text { Practices }\end{array}$ & $\begin{array}{c}\text { Reduced resources } \\
\text { for supply chain } \\
\text { value creation }\end{array}$ & $\begin{array}{c}\text { Reuse of resources } \\
\text { in the value chain }\end{array}$ \\
\hline Capital: & Logistics: & Recycling: & Reproduction: \\
\hline $\begin{array}{c}\text { Use of investment } \\
\text { and state financial } \\
\text { support }\end{array}$ & $\begin{array}{c}\text { Environmentally } \\
\text { friendly resource } \\
\text { logistics across } \\
\text { different market } \\
\text { sectors }\end{array}$ & $\begin{array}{c}\text { Differentiation of } \\
\text { raw materials into } \\
\text { components and } \\
\text { their further } \\
\text { recycling }\end{array}$ & $\begin{array}{c}\text { Converting } \\
\text { resources while } \\
\text { preserving original } \\
\text { forms }\end{array}$ \\
\hline \multicolumn{4}{|c|}{ Improving supply chain performance } \\
\hline Efficiency & Reliability & Flexibility & Sustainability \\
\hline
\end{tabular}

Today, no company can organize a completely transparent supply chain on its own. It requires the establishment of cooperation between partners using common standards and databases, due to which there is an acceleration of capacity development, smoothing of uncertainty in decision-making in joint work [2]. For example, more than 40 years ago in Europe and the United States, the automotive industry began to use electronic data exchange as a standard for planning delivery schedules to maintain waste-free production and on-time delivery.

Similarly, today's IBM, has solved the problem of creating smarter, safer, and more sustainable food supply systems by bringing together producers, suppliers, retailers, and other stakeholders into an ecosystem. The Blockchain solution has helped eliminate supply chain bottlenecks, improve reputation, safety, and compliance. 
Sustainable supply chains provide not only a competitive advantage, but also additional preferences for synergies, reducing deflationary opposition. Companies must have end-toend visibility throughout the chain and be able to track flows both upstream and downstream. Such practices are already in use, with an emphasis on the quality of data collection and exchange on technologies used in collaborative business processes $[3,4]$. It should be recognized that existing business cases for solution traceability and transparency tend to be industry-specific and require detailed elaboration of four key components (Tab.2).

Table 2. Components of the industry solution for supply chain visibility and traceability.

\begin{tabular}{|c|c|c|c|}
\hline \multicolumn{4}{|c|}{ Ility and traceability of the supply chain } \\
\hline \multicolumn{4}{|c|}{ Components of the industry solution } \\
\hline $\begin{array}{c}\text { Exchange } \\
\text { mechanism: }\end{array}$ & Digital Platform: & $\begin{array}{c}\text { Comprehensive } \\
\text { Toolkit: }\end{array}$ & $\begin{array}{c}\text { System } \\
\text { Certification: }\end{array}$ \\
\hline $\begin{array}{c}\text { Sharing data, } \\
\text { experience and } \\
\text { practices among } \\
\text { industries, } \\
\text { consumers, and } \\
\text { regulators. }\end{array}$ & $\begin{array}{c}\text { Analysis and } \\
\text { visualization of data } \\
\text { aggregated at the } \\
\text { company and } \\
\text { industry level in a } \\
\text { digital environment. }\end{array}$ & $\begin{array}{c}\text { Rationale for } \\
\text { decision making } \\
\text { based on } \\
\text { benchmarking and } \\
\text { analysis of resource } \\
\text { value creation. }\end{array}$ & $\begin{array}{c}\text { Confirmation of } \\
\text { certification of the } \\
\text { activities of supply } \\
\text { chain participants to } \\
\text { strengthen its } \\
\text { reliability. }\end{array}$ \\
\hline
\end{tabular}

In the process of data exchange, participants (partners) in integrated supply chains $[5,6]$ need to improve supporting technologies and analytical mechanisms to ensure efficient, reliable, and sustainable logistics systems. For this purpose, the leading operators should develop and promote logistics platforms [7-10], setting standards. Subsequently, other interested market players (manufacturers, technology and service providers, consumers, and other market actors) can join them. A flexible approach to creating a pilot project, will help align standards; form the basis for creating future versions of the platform; define a mechanism for scaling across the industry.

\section{Results and discussion}

The study of the features of the current state and specifics of supply chains allows us to establish a close relationship between the creation of an environment conducive to information exchange and the mobilization of value. The established connection should not generate high risks and displace inter-branch proportions of reproduction. Reformatted chains will be the main vector for further increasing the level of both external and internal consumption. The authors believe that the development of an effective logistics supply chain that meets the conditions of visibility and traceability can be carried out in several stages (see Fig.1).

Creating an environment conducive to information exchange.

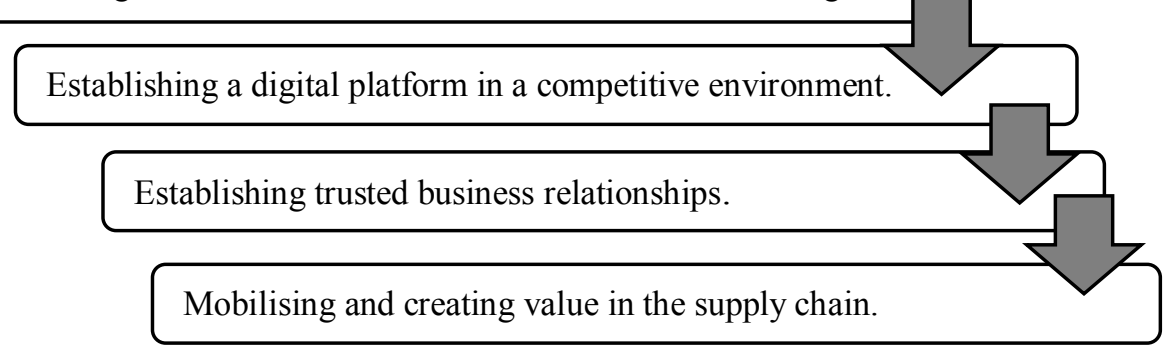

Fig. 1. The main stages of designing an effective logistics supply chain. 
Step 1: Creating an environment conducive to information exchange.

Companies must organize their work with partners and competitors in such a way as to achieve actual visibility and traceability of the entire chain, through the establishment of open communications. According to a survey conducted in January 2020 at the World Economic Forum, it was found that not all supply chain participants are willing to share internal data with competitors. Obviously, solving this problem will require the involvement of reliable independent organizations (Fig. 2), such as industry associations [11].

Question: "What organizations are you willing to share operational information with in exchange for access to industry-wide data?"

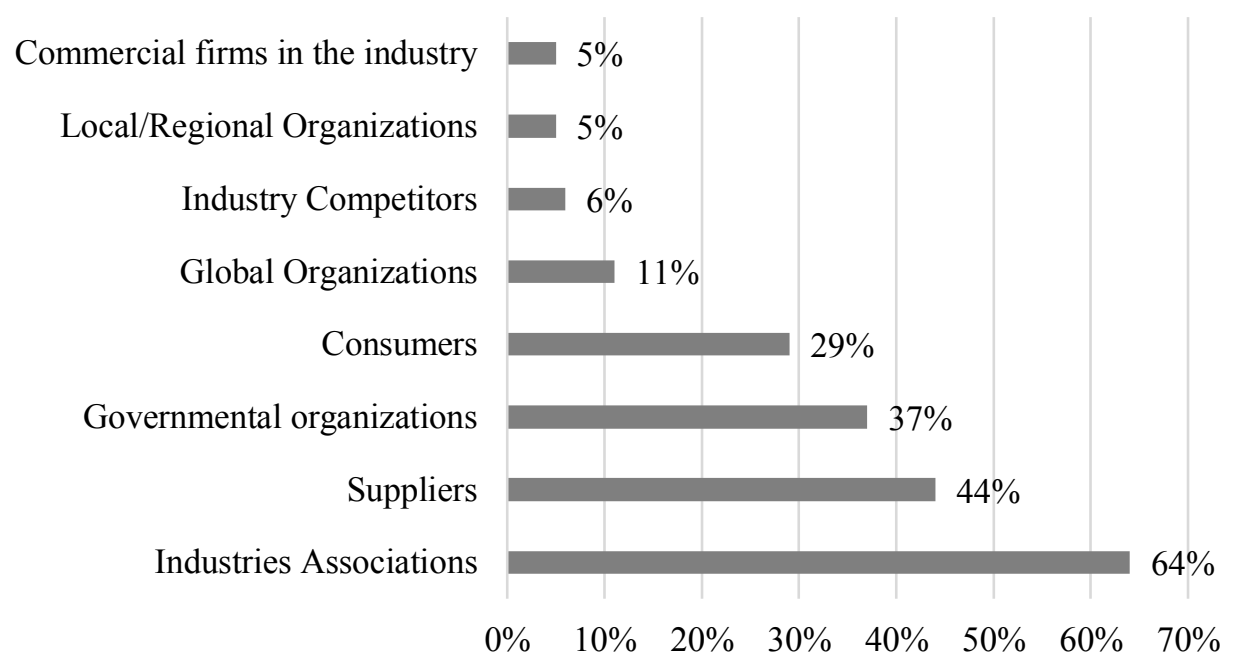

Fig. 2. Number of respondents in the industry willing to share information with other supply chain participants.

When forming an information sharing mechanism, it is necessary to use a common language and a consistent operating model that is flexible enough to scale from a pilot project to a sector-wide solution. In addition, it is important to ensure: first, objective representation of stakeholders in the decision-making process; second, the ability to cover ongoing operating and scaling costs; and third, incentives that will lead to improved supply chain performance.

Information sharing must also be accompanied by the sharing of experiences and best practices. To achieve this goal, independent organizations will need to bring stakeholders together and provide a mechanism for sharing information in accordance with industry standards. For example, some firms are already helping manufacturers, suppliers and logistics intermediaries involved in the supply chain automate and standardize processes using global standards language, such as the GTIN standard, which provides various globally recognized ways to add an identifier to a product, such as a barcode.

Stage 2: Establishing a digital platform in a competitive environment.

Nowadays, the digital platform [12], which represents a set of economically sustainable relationships arising between all independent participants in the supply chain, serves as the main platform that integrates various technological solutions. These relationships are formed in a single information environment that allows to optimize overall costs through the processing of large amounts of digital data at all levels of logistics integration. A logistics platform provides a secure exchange of information and expertise [13-15], and enables rapid 
resolution of operational challenges, facilitating connectivity to the modern supply chain ecosystem and making it more flexible (Fig. 3).

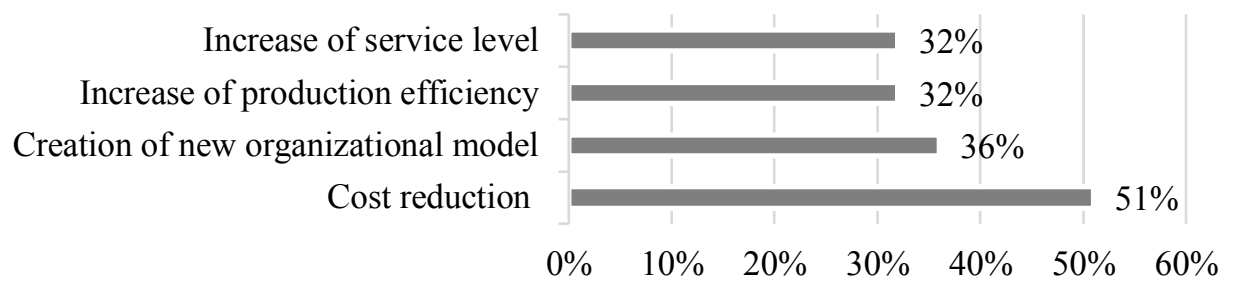

Fig. 3. Benefits of implementing digital platforms in the supply chain.

Given the pace at which innovation is spreading in the market, to ensure supply chain visibility and traceability, a technology company should commit to fully hosting and developing the platform, followed by the commercialisation of the solution. In doing so, the platform should be embedded into the analytics functions of the existing supply chain and integrated with it as needed, allowing users to visualize key information and provide decision support.

Step 3: Establishing trusted business relationships.

Developing collaboration between suppliers and customers in the digital platform involves entering a variety of business contracts that take into account the requirements of the supply chain. Strict monitoring of compliance with the terms and conditions of cooperation and systematic updating of the information repository will strengthen the longevity of business relationships. The authorisation of a digital platform and the variation of analytical results will help to establish more effective communication, encouraging the involvement of new companies in logistics.

Real-time data will point out issues affecting on-time delivery and cargo security. Close partnership with suppliers and the ability to collect information from supply chain counterparts will form the conditions for end-to-end visibility [14, 15] (Fig. 4).

Improved quality and traceability of delivery

Flexibly responding to demand changes

Improving customer relations

Improved service system

Flexibly responding to changes in supplier activity

Improving supplier relationships

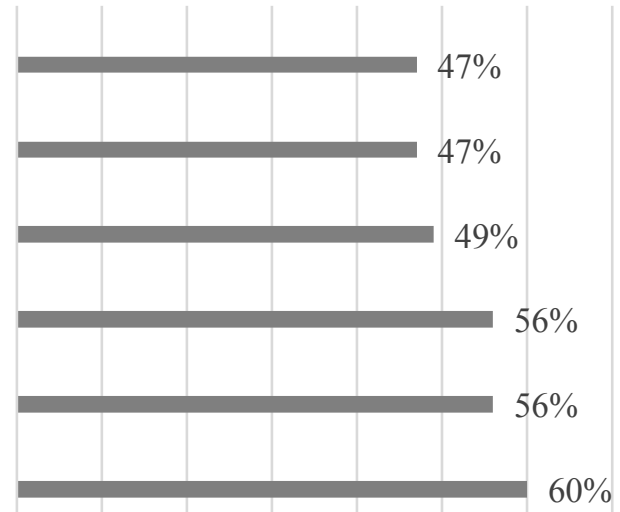

$\begin{array}{lllllllll}0 \% & 10 \% & 20 \% & 30 \% & 40 \% & 50 \% & 60 \% & 70 \%\end{array}$

Fig. 4. Supply chain end-to-end visibility conditions [15].

Creating end-to-end visibility and traceability in the supply chain through the establishment of cooperation between actors is challenging and requires an infusion of significant investment. 
Step 4: Mobilising and creating value in the supply chain.

In order to ensure transparency and traceability in the supply chain, each company involved must, on the basis of new knowledge, develop tools to manage its own [20] and joint efforts. In particular, guidance on creating the necessary resources, systems and processes; guidance on comparing performance and sectoral development progress; and guidance on assigning roles and responsibilities in supply chain value creation.

Designing a balanced supply chain requires a two-tiered approach, aiming for greater chain transparency and sector-wide collaboration. The first level: internally, the business needs to be structured around the uncertainties associated with innovation and step-by-step tactical and strategic plans need to be developed to address both current and potential challenges. Second level: outside the company, sectoral market actors facing similar challenges should be identified, whose joint resolution will establish a framework for delivery both within their industry and across all sectors.

The economic and technological component that forms between the businesses involved in the integrated supply chain correlates with each other. This results in transport and economic links, the physical expression of which is the flow of goods with value. Additionally, the value attached is a quantitative characteristic reflecting the value of the flow.

In creating value, companies will not have to put extra effort into maintaining the efficiency, reliability and sustainability of the supply chain, and increased visibility and traceability will provide the necessary amount of data about each element. A holistic view will optimise the business processes taking place, manage their interrelationships and reduce potential trade-offs.

\section{Conclusions}

A supply chain's ability to recover, redirect or replace resources, while maintaining its reliability and efficiency, through increased visibility and traceability, will improve the architecture of relationships between partners. Sustainable supply chains provide not only a competitive advantage, but also an additional preference for synergies by reducing deflationary opposition. In doing so, leading operators should develop and promote logistics platforms, setting standards to which other interested market players can subsequently subscribe. Shaping an efficient supply chain that meets the conditions of visibility and traceability is a qualitatively new approach to fragmented logistics process design, based on a value system centred on a new code and digital mindset, with a cognitive platform at its core. This approach to shaping the industry solution for designing efficient supply chains has application and helps companies meet the growing needs of stakeholders for sustainable distribution channels, by:

- Organising with partners and competitors by establishing open communications, as the sharing of best practices and sector-wide collaboration provide unlimited opportunities for supply chain visibility and traceability;

- Implementing a digital platform that enables secure sharing of data and expertise, enables rapid tactical solutions, and makes it easier to connect to the modern supply chain ecosystem and make it more agile;

- authorisation of the digital platform and variation of analytical results, helping to establish better business links and stimulate the involvement of new companies in logistics;

- Ensuring supply chain visibility and traceability by managing proprietary and collaborative efforts to create value for improving economies of scale and reducing inventories.

The industry's commitment to improving supply chain visibility and traceability is aimed at helping partners and consumers purchase safe and quality products; gaining the ability to 
track returns, defects and manage recalls; and focusing efforts on improving the sustainability and reliability of the country's logistics system in the near term.

\section{References}

1. H. Saenz, J. Stephan, J. Terino, T. Bysong, J. Gnamm, How to Trace a Path to Resilient, Sustainable Supply Chains (Bain \& Company, Inc. 2020)

2. S. Suvorova, A. Tevanyan, IOP Conference Series: Materials Science and Engineering, 940(1), 012049 (2020)

3. M. Imran, A. Hamid, A.B. Aziz, W. Ul-Hameedb, Uncertain Supply Chain Management, 7, 1, 36 - 72 (2019)

4. D.R. Gnimpieba, A. Nait-Sidi-Moha, D. Durandb, J. Fortina, Using Internet of Things technologies for a collaborative supply chain: Application to tracking of pallets and containers, International Workshop on Mobile Spatial Information Systems (MSIS 2015)

5. A. Guedson, Supply Chain Management in the Motor Vehicle Industry, the Example of Mini, URL: https://www.automotivecouncil.co.uk/

6. O.V. Karpun, Intellectualization of Logistics and Supply Chain Management 4 (4), 41$52(2020)$

7. A. Swaroop, LBS Journal of Management \& Research, 10 (2), 35-40 (2012)

8. R. Hull, E. Damaggio, F. Fournier, M. Gupta, et al, Introducing the Guard-StageMilestone Approach for Specifying Business Entity Lifecycles. Preprint from Proc. Intl.Workshop on Web Services and Formal Methods (WS-FM, 2010)

9. Digital platforms trends in 2018: evolution of business models (2017) URL: https://seanews.ru/2017/11/30/kitajskaja-nacionalnaja-platforma-dl/ (date of access 27.04.2020)

10. Supply Chain Traceability Survey, July 2020, N=131; expert interview (2020) URL: https://mitsloan.mit.edu/

11. N. Rožman, R. Vrabič, M. Corn, T. Požrl, J. Diaci, Procedia CIRP, 81, 826-831 (2019)

12. A.V. Dmitriev, I.A. Plastunyak, Integrated digital platforms for development of transport and logistics services, International Conference on Digital Transformation in Logistics and Infrastructure, Saint-Petersburg: Atlantis Highlights in Computer Sciences, 2019, p. 136-141 (2019)

13. S.P. Choudary, M.W. Van Alstyne, G.G. Parker, Harvard Business Review, 1 (2019)

14. P.J. Benghozi, S. Bureau, F. Massit-Folléa, The Internet of Things: What are the challenges for Europeans, Ministry of Research, Delegation for Internet uses (Paris, 2008)

15. E. Korchagina, S. Barykin, S. Suvorova, A. Bochkarev, P. Bochkarev, E3S Web of Conferences. Innovative Technologies in Environmental Science and Education, 02016 (2019) 